\title{
Thalidomide and its analogues in the treatment of Multiple Myeloma
}

\author{
Tahir Latif ${ }^{1}$, Nabeel Chauhan², Rashid Khan ${ }^{3}$, Andrea Moran ${ }^{3}$ and Saad Z Usmani ${ }^{*}$
}

\begin{abstract}
Multiple myeloma is an incurable malignant disorder of mature B-cells that predominantly affects the elderly. The immunomodulatory drug (IMiD) thalidomide and its newer analogs demonstrate increased antitumor activity, and have had a positive impact on the natural history of multiple myeloma. Recent advances in the clinical application of these agents and in our understanding of their mechanism of action, and toxicity have made safer and smarter use of these drugs possible. This review discusses the available information regarding mechanisms of action, toxicity and clinical results on thalidomide, lenalidomide and pomalidomide in the therapy of multiple myeloma.
\end{abstract}

Keywords: Multiple Myeloma, Thalidomide, Lenalidomide, Pomalidomide, Therapy

\section{Introduction}

Multiple myeloma is a mature B-cell neoplasm characterized by a monoclonal expansion of plasma cells in the bone marrow often accompanied by hemocytopenias, immunodeficiency, osteolytic lesions, hypercalcemia and renal failure. Myeloma accounts for about $10 \%$ of all hematological malignancies and $1 \%$ of all cancers [1]. In United States alone an estimated 20,520 new cases (11,400 men and 9120 women) will be diagnosed in 2011 and 10,610 people will die of myeloma [2]. Ever since the first reported case of 'mollities ossium' described in 1844 [3], the disease has remained incurable, despite a better understanding of its pathogenesis and recent advancements in therapeutics. Prior to the advent of alkylating agents, the median survival for multiple myeloma was 1-1.5 years [4]. Following the introduction of L-phenylalanine mustard or melphalan in 1958 [5] and prednisone in 1962 [6], the combination of these two drugs remained the cornerstone of therapy for more than two decades, even though the complete remission rate remained less than $5 \%$ and the median survival with this treatment did not exceed 3 years [7]. Since the late 1990s, a number of new classes of drugs have been incorporated in the treatment of multiple myeloma and additional agents are under investigation

\footnotetext{
* Correspondence: susmani@uams.edu

${ }^{2}$ Myeloma Institute for Research \& Therapy, University of Arkansas for Medical Sciences, 4301 W. Markham Street, Little Rock, AR, USA

Full list of author information is available at the end of the article
}

(Figure 1). The present paper will review the clinical data for the use of thalidomide and its analogs, collectively referred as immunomodulatory drugs or IMiDs in multiple myeloma.

\section{The history and toxicity of immunomodulatory drugs (IMiDs)}

Thalidomide was first introduced as an oral sedative and anti-emetic in 1957, but was quickly abandoned due to its profound teratogenic effects. Almost four decades passed before studies demonstrated thalidomide to have anti-cancer properties, specifically showing significant in vitro anti-myeloma activity. It found its use as a novel anti-myeloma drug for relapsed and refractory disease in 1999 [8], later yielding impressive overall response rates of up to $50 \%$ when used in combination with dexamethasone and up to $65 \%$ when combined with corticosteroids and cyclophosphamide [9]. Thalidomide, though effective, was associated with dose-limiting toxicities including somnolence, constipation, neuropathy [10], and increased incidence of venothromboembolism (VTE), especially when combined with dexamethasone [11]. Hence, a new class of thalidomide derivatives called IMiDs was developed that, albeit structurally related (Figure 2, Table 1), had their unique set of anti-inflammatory, immunomodulatory, antiproliferative, antiangiogenic and toxicity profiles [12].

Lenalidomide (CC 5013) was FDA approved for use in patients with relapsed and/or refractory multiple

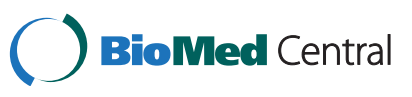

(c) 2012 Latif et al.; licensee BioMed Central. This is an Open Access article distributed under the terms of the Creative Commons Attribution License (http://creativecommons.org/licenses/by/2.0), which permits unrestricted use, distribution, and reproduction in any medium, provided the original work is properly cited. 


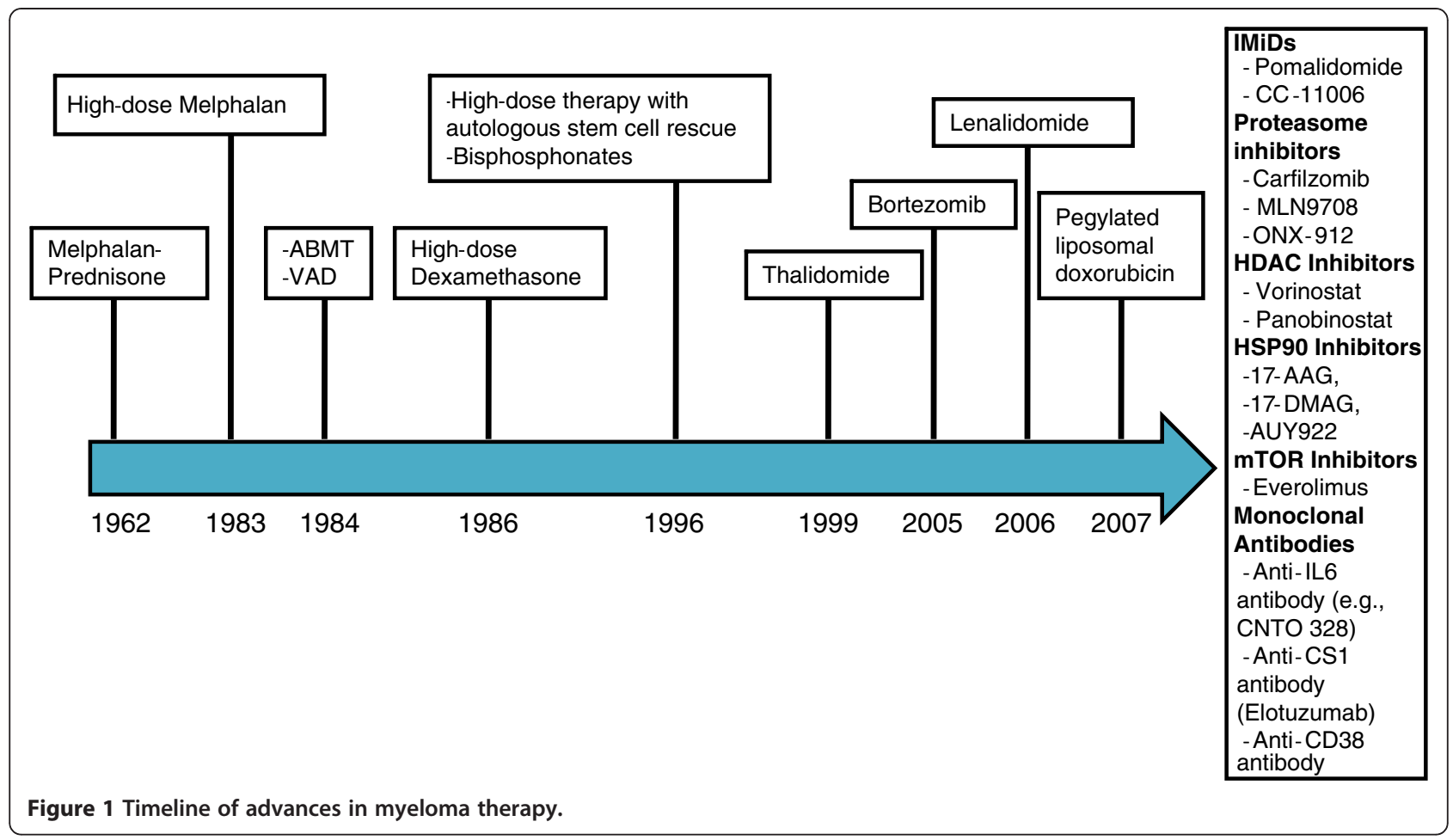

myeloma after successful clinical trials $[13,14]$. Lenalidomide has a distinct adverse effect profile compared to thalidomide. Notably, there is an increased risk of grade 3 , or greater myelosuppression; however, the rates of sedation, constipation and neuropathy are all lower than thalidomide. The risk of VTE varies among studies, and is dependent on age, concurrent chemotherapy including dexamethasone, and the use of VTE prophylactic agents. Importantly, lenalidomide adversely affects adequate peripheral blood stem cell collection in older patients with therapy duration greater than 4 months $[15,16]$. More recently, several investigators have reported an alarmingly high rate of second malignancies, both myelodysplastic syndrome/acute myeloid leukemia and solid tumors in newly diagnosed patients with multiple myeloma receiving maintenance lenalidomide after autologous stem cell transplant (Table 2) [17-19]. However, additional data reported in 2011 Annual Meeting of American Society of Clinical Oncology did not show any increase in the rate of second malignancies in transplant ineligible and relapse or refractory patients undergoing lenalidomide therapy [20-22]. For example pooled data from MM-009/010 trials evaluating lenalidomide and dexamethasone versus dexamethasone/placebo and a phase II trial evaluating clarithromycin, dexamethasone and lenalidomide in 72 newly diagnosed multiple myeloma patients found similar frequency of second malignancies to background incidence and 2010 SEER data respectively for non-Multiple Myeloma individuals of similar age.

Pomalidomide (CC-4047), another derivative of thalidomide has shown promising activity in phase I/II trials in relapsed and refractory multiple myeloma patients, including patients who have been treated with thalidomide, lenalidomide and the $26 \mathrm{~S}$ proteasome inhibitor bortezomib (PS-341) [23-26]. Overall pomalidomide was well tolerated, with thromboembolic events the major non-hematological dose limiting toxicity, while<smiles>O=C1CCC(N2C(=O)c3ccccc3C2=O)C(=O)N1</smiles>

Thalidomide<smiles>Nc1cccc2c1CN(C1CCC(=O)NC1=O)C2=O</smiles>

Lenalidomide<smiles>Nc1cccc2c1C(=O)N(C1CCC(=O)NC1=O)C2=O</smiles>

Pomalidomide

Figure 2 Molecular stutctures of the IMiD. 
Table 1 Pharmacokinetics of the IMiDs

\begin{tabular}{llllll}
\hline Drug & Route of administration & Dosage & Metabolism/Excretion & Half-life & Dose adjustments \\
\hline Thalidomide & Oral & $50-100 \mathrm{mg}$ & Hepatic/Non-renal & $4-9$ hours & None at present \\
Lenalidomide (CC-5013) & Oral & $15-25 \mathrm{mg}$ & Renal (67\% unchanged) & $3.1-4.5$ hours & $\begin{array}{l}\text { Adjust for moderate to severe } \\
\text { renal impairment }\end{array}$ \\
Pomalidomide (CC-4047) & Oral & $1-5 \mathrm{mg}$ & Renal (67\% unchanged) & $6.2-7.9$ hours & None at present \\
\hline
\end{tabular}

neutropenia was the most common dose-limiting toxicity noted in initial phase 1 study. Peripheral neuropathy was reported by up to $30 \%$ of patients; however, the majority of these were reversible grade 1toxicity $[23,24]$.

\section{Mechanisms of action}

The mechanism of action of the IMiDs is not completely understood. They are thought to possess anti-proliferative, anti-angiogenic and immunomodulatory effects against myeloma cells. Lenalidomide and pomalidomide exert their anti-myeloma effect dually through direct down-regulation of key functions of the tumor cell, and indirectly by modulating interaction of myeloma cells with their microenvironment. They carry out their direct effects via modulation of cell adhesion and decreasing production of key pro-survival cytokines such as TNFalpha, IL-6, IL-8, and VEGF that favor tumor cell survival and proliferation, inhibition of apoptosis, and resistance to therapy [27].

Both lenalidomide and thalidomide inhibit TNFalpha production by increasing the degradation of TNFalpha mRNA and by increasing the activity of alpha-1-acid glycoproteins, which have intrinsic anti-TNFalpha activity [28]. In addition to the anti-angiogenic effect of thalidomide, IMiDs have further shown to directly induce apoptosis by triggering the activation of caspase-8, which in turn induces myeloma cell death via Fas-mediated pathways. Dexamethasone also activates caspase-9 pathway, hence forming the basis of its synergy with the IMiDs. Lenalidomide also utilizes mitochondrial pathways to release pro-apoptotic proteins such as cytochrome c and Smac [29]. Dexamethasone too, has been shown to release Smac, but not cytochrome c, in myeloma cells, hence providing further molecular basis for the additive effects of the two drugs, as seen in clinical trials.

IMiDs have shown to down-regulate NF- $\mathrm{kB}$ transcription activity in vitro, and in effect blunt out the survival advantage that myeloma cells employ in tumorigenesis. Dexamethasone has also been shown to down regulate NF- $\mathrm{kB}$ activity, and coupled with lenalidomide nearly abrogates NF- $\mathrm{kB}$ activity in myeloma cells [30]. The net effect is inhibition of caspase inhibitors, induction of caspase- 8 activity, and promotion of Fas- and TRAIL/ Apo2L-induced apoptosis. IMiDs also block the stimulatory effect of insulin like growth-factor-1 on NF- $\mathrm{KB}$ activity and potentiate the activity of dexamethasone and proteasome inhibitor therapy.

Furthering their immune modulatory role, the IMiDs also affects other cellular components in the bone marrow. In preclinical studies they have demonstrated activation of $\mathrm{T}$ and NK cells [31-33]. Lenalidomide induces T-cell proliferation, mainly by co-stimulation of CD28 that in turn leads to increased transcription and production of IL-2 and IFN-gamma. It is in fact many times more potent than its predecessor. As a result of increased T-cell derived IL-2 and IFN-gamma, and lenalidomide and pomalidomide have been shown to augment CD 56+ NK cell numbers and function [34].

In addition to its diverse immunomodulatory effects, lenalidomide, although a weaker inhibitor of angiogenesis than thalidomide, has a well-documented antiangiogenic profile. Instead of directly inhibiting endothelial cell proliferation like its predecessor, lenalidomide in fact inhibits the secretion of vascular endothelial growth factor (VEGF) and basic fibroblast growth factor (bFGF), from both tumor and stromal cells [35]. Lenalidomide inhibits Akt phosphorylation, hence interrupting the

Table 2 Lenalidomide and incidence of second primary malignancies

\begin{tabular}{|c|c|c|c|c|}
\hline Study & Patient population & Treatment & Numbers & SPM \\
\hline \multirow[t]{3}{*}{ MM-015 } & Elderly transplant ineligible patients & MP & 153 & $(3 \%)$ \\
\hline & & MPR & 152 & $(7 \%)$ \\
\hline & & MPR-R & 150 & (7\%) \\
\hline \multirow[t]{2}{*}{ IFM 2005-02 } & Newly diagnosed post stem cell transplant & Placebo & 302 & $11(4 \%)$ \\
\hline & & Lenolidomide & 306 & $26(8 \%)$ \\
\hline \multirow[t]{2}{*}{ CALGB 100104} & Newly diagnosed post stem cell transplant & Placebo & 229 & $6(2.6 \%)$ \\
\hline & & Lenolidomide & 231 & $18(7.8 \%)$ \\
\hline
\end{tabular}


Table 3 Clinical trials-thalidomide (Relapsed/refractory disease)

\begin{tabular}{|c|c|c|c|c|c|c|c|}
\hline Author & Regimen & $\begin{array}{l}\text { Type of } \\
\text { clinical trial }\end{array}$ & No. of pts & $\begin{array}{l}\text { Best responses } \\
\text { (>PR) }\end{array}$ & CR, nCR, VGPR & $\begin{array}{l}\text { PFS/TTP/OS } \\
\text { (months) }\end{array}$ & Reference \\
\hline Barlogie et al & $\mathrm{T}$ & Phase II & 169 & $30 \%$ & CR:2\% & 2 yr EPS:20\% 2 yr OS;48\% & Blood 2001 \\
\hline Palumbo et al & TD & Phase II & $\begin{array}{l}62(\mathrm{FR}) \\
58(\mathrm{SR})\end{array}$ & $\begin{array}{l}56 \%(F R) \\
46 \%(S R)\end{array}$ & Not reported & $\begin{array}{l}\text { PPS:17(FR), } 11(\text { SR) } \\
\text { OS:60\%(FR,3-yr),19(SR) }\end{array}$ & Hematol J 2004 \\
\hline Dimpopoulus et al & TD & Phase II & 44 & $55 \%$ & $>$ VGPR:30\% & Median survival 12.6 & Annal Oncol 2001 \\
\hline Moehler et al & DT-PACE & Phase II & 50 & $65 \%$ & CR:4\% & PPS:15 1 yr OS:63\% & Bllod 2001 \\
\hline Terpos E et al & VMDT & Phase II & 62 & $66 \%$ & CR:13\% VGPR:27\% & TTP: 9.7 & Leukemia 2008 \\
\hline Palumbo et al & VMDT & Phase II & $30 \%$ & $67 \%$ & VGPR:43\% & $\begin{array}{l}\text { PPS (1 yr):61\% OS } \\
(1 \mathrm{yr}): 84 \%\end{array}$ & Blood 2007 \\
\hline
\end{tabular}

phosphatidylinositol 3-kinase (PI3K)/Akt signaling pathway, known to be integral in tumor cell survival and proliferation. Inhibition of this pathway, downstream of VEGF signaling may explain in part the drug's antiproliferative and anti-angiogenic effects. Lenalidomide also inhibits VEGF-induced PI3K-Akt pathway signaling, which is known to regulate adherens junction formation. A strong inhibitory effect of lenalidomide on hypoxiainduced endothelial cell formation of cords and hypoxiainducible factors (HIF-1) alpha expression, the main mediator of hypoxia-mediated effects and a key driver of angiogenesis and metastasis, has also been found [36]. Pomalidomide and lenalidomide also demonstrated their potential in epigenetic modulation of p21 WAF-1 expression, thereby possibly being efficacious in p53 mutated tumors [37].

Recent landmark discovery of cereblon (CRBN), an essential protein to induce thalidomide teratogenicity in zebrafish and chicken embryos, led to several presentations at 2011 American society of Hematology (ASH) meeting demonstrating the critical role of CRBN in antiproliferative response to IMiDs [38,39]. Majority of myeloma cell lines and patients resistant to IMiDs showed very low levels of CRBN [40]. In addition, bone marrow
CRBN mRNA expression was also predictive of response to lenalidomide and dexamethasone in small study of 44 patients [41].

\section{Clinical data}

\section{Thalidomide}

Thalidomide-based chemotherapy combinations are currently considered front-line regimens in both transplant eligible and transplant ineligible patients. Initial phase I data was first described in patients with relapsed and refractory multiple myeloma in 1999 by Singhal et al [9]. A number of subsequent trials utilizing thalidomide combinations have demonstrated overall response rates of $46 \%-67 \%$ for relapsed and refractory disease (summarized in Table 3).

Four different phase III trials have evaluated the use of thalidomide in combination with melphalan/prednisone (MP) in comparison with MP in transplant in-eligible patients (Table 4). One of the four trials added thalidomide maintenance until relapse [42]. The MPT regimen demonstrated superior overall responses and complete responses compared to $\mathrm{MP}$ in two of these trials. Although Palumbo et al. also showed improved overall responses in comparison to $\mathrm{MP}$, but the initial difference

Table 4 Clinical trials-thalidomide (Transplant Ineligible)

\begin{tabular}{|c|c|c|c|c|c|c|c|}
\hline Author & Regimen(s) & $\begin{array}{l}\text { Type of } \\
\text { clinical } \\
\text { trial }\end{array}$ & No. of pts & $\begin{array}{l}\text { Best responses } \\
\text { (>PR) }\end{array}$ & CR, nCR, VGPR & $\begin{array}{l}\text { PFS/TTP/OS } \\
\text { (months) }\end{array}$ & Reference \\
\hline Palumbo et al & $\begin{array}{l}\text { MPT+T maintenance } \\
\text { vs. MP }\end{array}$ & Phase III & 255 & $76 \%$ vs $47.6 \%$ & CR: $15.5 \%$ vs. $2.2 \%$ & $\begin{array}{l}\text { OS: } 45 \text { vs. } 47.6 \\
\text { PPS: } 21.8 \text { vs. } 14.5\end{array}$ & Blood 2008 \\
\hline Facon et al & $\begin{array}{l}\text { MPT vs MP } \\
\text { vs. HDT/ASCT }\end{array}$ & Phase III & 427 & $\begin{array}{l}89 \% \text { vs } 37 \% \\
\text { vs } 83 \%\end{array}$ & $\begin{array}{l}\text { CR: } 13 \% \text { vs. } 2 \% \text { vs. } \\
18 \% \text { VGPR: } 47 \% \text { vs. } \\
7 \% \text { vs. } 43 \%\end{array}$ & $\begin{array}{l}\text { OS: } 51.6 \text { vs. } 33.2 \\
\text { vs. } 38.3\end{array}$ & Lancet 2007 \\
\hline Hulin et al & MPT vs MP & Phase III & 229 & $69 \%$ vs $39 \%$ & $\begin{array}{l}\text { CR: } 7 \% \text { vs } 1 \% \\
\text { VGPR: } 22 \% \\
\text { Vs. } 7 \%\end{array}$ & $\begin{array}{l}\text { OS: } 45.3 \text { vs. } 27.7 \\
\text { PPS: } 24.1 \text { vs. } 19.0\end{array}$ & $\begin{array}{l}\text { Blood (ASH Annual } \\
\text { Meeting) 2007; } \\
\text { 110:75 (abstr) }\end{array}$ \\
\hline Ludwig et al & MPT vs. MP & Phase III & 231 & $68 \%$ vs $51 \%$ & $\begin{array}{l}\text { CR: } 14 \% \text { vs. } 7 \% \\
\text { nCR: } 17 \% \text { vs. } 8 \% \\
\text { VGPR: } 17 \% \text { vs. } 14 \%\end{array}$ & $\begin{array}{l}\text { OS: } 45 \text { vs. } 58 \text { EPS: } 25 \\
\text { vs. } 43\end{array}$ & $\begin{array}{l}\text { Blood (ASH Annual } \\
\text { Meeting) 2007; } \\
110: 529 \text { (abstr) }\end{array}$ \\
\hline Palumbo et al & MPT & Phase $\mid / \|$ & 53 & $81 \%$ & CR:23.8\% VGPR:47.6\% & 1 yr EPS:92\% 1 yr OS:100\% & J Clin Oncol 2007 \\
\hline
\end{tabular}


Table 5 Clinical trials-thalidomide (Transplant Eligible)

\begin{tabular}{|c|c|c|c|c|c|c|c|}
\hline Author & Regimen(s) & $\begin{array}{l}\text { Type of } \\
\text { clinical trial }\end{array}$ & No. of pts & $\begin{array}{l}\text { Best responses } \\
\text { (>PR) }\end{array}$ & CR, nCR, VGPR & $\begin{array}{l}\mathrm{PFS} / \mathrm{TTP} / \mathrm{OS} \\
\text { (months) }\end{array}$ & Reference \\
\hline Rajkumar et al & TD vs. D & Phase III & 470 & $63 \%$ VS. $46 \%$ & $\begin{array}{l}\text { CR+VGPR: } 44 \% \\
\text { Vs. } 16 \%\end{array}$ & TTP:22.6 vs. 6.4 & J Clin Oncol 2008 \\
\hline Lockhorst et al & TAD vs. VAD & Phase III & 402 & $72 \%$ VS. $54 \%$ & NR & NR & Haematologica 2008 \\
\hline Cavo et al & VTD vs. TD & Phase III & 187 & $93 \%$ VS. $79 \%$ & NR & NR & ASH 2007 \\
\hline Barlogie et al & VTD-PACE & Phase II & 303 & $99 \%$ & $\begin{array}{l}\text { nCR:83\% (2 yr) CR: } \\
56 \%(2 \mathrm{yr})\end{array}$ & $\begin{array}{l}\text { EFS:84\% (2 yr) OS: } \\
86 \%(2 \text { yr) }\end{array}$ & B J Hematol 2007 \\
\hline
\end{tabular}

in overall survival was not seen with longer follow-up, questioning the justification of thalidomide maintenance. One of these trials evaluated the optimal treatment strategy in the elderly MM patients by comparing MP, MPT and high-dose therapy/autologous stem cell transplant [43]. This trial showed that MPT had better overall survival than the other two arms. Based on these trials, MPT is considered a front-line regimen for transplant ineligible and elderly MM patients.

Thalidomide-based combinations have also been evaluated as induction regimen for transplant-eligible myeloma patients (Table 5). It has been observed that combination of 2 novel agents results in better depth of response, as seen in combination of thalidomide with bortezomib and dexamethasone (VTD). The VTD is often the induction regimen of choice outside of clinical trials, with overall response rates of 93\%. Currently three-novel drug and four-novel drug regimens are being evaluated in clinical trials for safety and efficacy. This strategy certainly holds promise judging by the encouraging results of the Total Therapy 3 data (utilizing VTDPACE), demonstrating that combining all active antimyeloma agents upfront results in overall responses approaching $100 \%$, and $87 \%$ of the complete responders remain disease free four years from initial therapy [44].

Thalidomide had also been evaluated as maintenance therapy in several trials. As an example, the recently published MRC Myeloma IX trial showed statistically significant improvement in progression free survival, 23 vs. 15 months; log-rank $P<0.001$, in patients receiving low dose (50 to $100 \mathrm{mg}$ ) thalidomide maintenance as compared to placebo. There was no significant difference in median overall survival $P=0.40$. However, a meta-analysis performed by same authors including additional data from other published studies evaluating thalidomide maintenance showed significant late survival benefit $P<0.001$ [45].

\section{Lenalidomide}

In recent years, lenalidomide has become the lead IMiD in myeloma clinical investigation due to its superior safety profile. Two phase II trials have looked at the efficacy of lenalidomide and dexamethasone in comparison to dexamethasone alone, showing superior overall responses, complete response and overall survival (Table 6). This combination is also superior to dexamethasone alone in newly diagnosed patients (Table 7). The efficacy of this combination was marred by the unacceptably high rates of venous thromboembolism (26\%). An ECOG phase III trial comparing low-dose dexamethasone to previously utilized high-dose dexamethasone, found not only reduction in VTE rates $(12 \%)$ in the low-dose group, but also an improved overall survival at the first interim analysis resulting in suspension of the study [46]. The high-dose group was subsequently switched to the low dose dexamethasone regimen. Niesvizky et al. have shown in a phase II study that addition of clarithromycin to lenalidomide and dexamethasone (BiRD) results in a higher overall response rate [47].

With the successful results of combining MP with thalidomide and then with bortezomib in the elderly myeloma population, the addition of lenalidomide to MP was assessed by Palumbo et al. in a phase I/II trial [48]. The study demonstrated overall response of $81 \%$ with majority of these patients achieving a very good partial response (VGPR) or better. The results have led to initiation of an ECOG phase III trial comparing MPT

Table 6 Clinical trials-lenalidomide (Relapsed/refractory disease)

\begin{tabular}{|c|c|c|c|c|c|c|c|}
\hline Author & Regimen(s) & $\begin{array}{l}\text { Type of clinical } \\
\text { trial }\end{array}$ & No. of pts & $\begin{array}{l}\text { Best responses } \\
(>P R)\end{array}$ & CR, nCR, VGPR & $\begin{array}{l}\text { PFS/TTP/OS } \\
\text { (months) }\end{array}$ & Reference \\
\hline Dimopoulus et al & LD & Phase III & 351 & $60.2 \%$ vs. $24 \%$ & CR+nCR:15.9\% vs. $3.4 \%$ & $\begin{array}{l}\text { TTP:11.7 vs. } 4.7 \\
\text { OS:Not reached } \\
\text { vs. } 20.7\end{array}$ & N Engl J Med 2007 \\
\hline Weber et al & LD & Phase IIII & 353 & $61 \%$ vs. $19.9 \%$ & CR:14.4 vs. $0.6 \%$ & $\begin{array}{l}\text { TTP:11.7 vs. } 4.7 \\
\text { OS:29.6 vs. } 20.2\end{array}$ & N. Engl J Med 2007 \\
\hline Palumbo et al & MPL-L & Phase III & 459 & $77 \%$ vs. $49 \%$ & CR:18\% vs. $5 \%$ & Not reached & ASH 2009 ASCO 2010 \\
\hline
\end{tabular}


Table 7 Clinical trials-lenalidomide (Newly diagnosed)

\begin{tabular}{|c|c|c|c|c|c|c|c|}
\hline Author & Regimen(s) & $\begin{array}{l}\text { Type of } \\
\text { clinical } \\
\text { trial }\end{array}$ & No. of pts & $\begin{array}{l}\text { Best responses } \\
(>\mathrm{PR})\end{array}$ & CR, nCR, VGPR & PFS/TTP/OS & Reference \\
\hline Rajkumar et al & Ld vs. LD & Phase III & 445 & $79 \%$ vs. $69 \%$ & $\begin{array}{l}\text { CR/nCR:18\% vs. } 14 \% \\
\text { VGPR:33\% vs. } 26 \%\end{array}$ & $\begin{array}{l}\text { 1-year OS:96\% } \\
\text { vs. } 87 \%\end{array}$ & Lancet Oncol 2010 \\
\hline Zonder et al & LD vs. D & Phase III & 133 & $85 \%$ vs. $51 \%$ & NR & Not reported & ASH 2007 \\
\hline Richardson et al & LVD & Phase I/II & 35 (Phase II) & $100 \%$ & VGPR:69\% CR + nCR:54\% & $\begin{array}{l}\text { Not reached at } 19.3 \\
\text { months (median) }\end{array}$ & ASH 2009 \\
\hline Jakubowiak et al & LV-PLD-D & Phase I/II & 26 (Phase II) & $96 \%$ & VGPR:67\% CR + nCR:33\% & $\begin{array}{l}\text { Not achieved at } 6 \\
\text { months (median) }\end{array}$ & ASH 2009 \\
\hline Kumar et al & $\begin{array}{l}\text { LCD vs. VCD } \\
\text { vs. LCVD }\end{array}$ & Phase II & 117 & $\begin{array}{l}90 \% \text { vs. } 87 \% \\
\text { vs. } 94 \%\end{array}$ & $\begin{array}{l}\text { VGPR: } 33 \% \text { vs. } 35 \% \text { vs. } \\
42 \% \text { CR: } 12 \% \text { vs. } 6 \% \\
\text { vs. } 15 \%\end{array}$ & Not reported & ASH 2009 \\
\hline Niesvizky et al & $\begin{array}{l}\text { Clarithromycin } \\
+L D\end{array}$ & Phase II & 72 & $90.3 \%$ & $\begin{array}{l}\text { VGPR:16.7\% CR + } \\
\text { sCR:38.9\% }\end{array}$ & $\begin{array}{l}\text { Actuarial EFS (2yr): } \\
\text { 85.2\% (transplant), } \\
75.2 \% \text { (non-transplant) }\end{array}$ & Blood 2008 \\
\hline Palumbo et al & MPL & Phase I/II & 54 & $81 \%$ & VGPR:47.6\% CR:23.8\% & $\begin{array}{l}\text { EFS }(1 \mathrm{yr}): 92 \% \text { OS } \\
(1 \mathrm{yr}): 100 \%\end{array}$ & JCO 2007 \\
\hline
\end{tabular}

with MPL as the first line therapy for newly diagnosed transplant ineligible myeloma patients.

A number of phase I and II trials are also presently exploring the combination of lenalidomide with other novel anti-myeloma agents. Promising results have been observed with the combination of lenalidomide, dexamethasone and bortezomib in both newly diagnosed and relapsed/refractory patients. Updated analysis of phase I/II trial reported at ASH 2011 showed an overall response rate of 98\%, including $71 \%$ VGPR and 36\% CR/nCR for 68 newly diagnosed patients, response rate was $100 \%$ for 52 patients treated at maximum planned dose [49]. Similarly impressive results were seen in relapse/refractory patients with median time to progression of almost 10 months and response rate of $78 \%$ including $25 \%$ complete response [50].

Based on these observations, an ongoing MMRC sponsored phase I/II trial evaluating the combination of lenalidomide, dexamethasone, bortezomib and liposomal doxorubicin as first line therapy in newly diagnosed patients showed greater than $96 \%$ partial response with $30 \%$ complete response in 57 evaluable patients [51]. A Mayo Clinic lead randomized phase II trial is comparing the combination of bortezomib, cyclophosphamide, lenalidomide and dexamethasone with either bortezomib or lenalidomide with cyclophosphamide and dexamethasone [52]. Although initial reports of these studies demonstrate unprecedented overall response rates for the four-drug combinations. It remains to be seen whether the depth of response may lead to similar success, and potentially, cures such as observed in aggressive lymphomas.

Lenalidomide had also shown promising activity as maintenance therapy after autologous stem cell transplant, e.g. McCarthy et al. [17] showed median time to progression of 46 months vs. 27 months $(\mathrm{P}<0.001)$ and Attal et al. [18] showed median progression-free survival of 41 months, vs. 23 months $(\mathrm{P}<0.001)$ in the lenalidomide and placebo groups respectively $[19,20]$. Lenalidomide was also evaluated in transplant ineligible patients as part of initial and maintenance therapy. In this trial patients received melphalan, prednisone, lenalidomide (MPR) as

Table 8 Clinical trials-pomalidomide

\begin{tabular}{|c|c|c|c|c|c|c|c|}
\hline Author & Regimen(s) & $\begin{array}{l}\text { Type of disease/ } \\
\text { clinical trial }\end{array}$ & No. of pts & $\begin{array}{l}\text { Best responses } \\
\text { (>PR) }\end{array}$ & CR, nCR, VGPR & $\begin{array}{l}\text { PFS/TTP/OS } \\
\text { (months) }\end{array}$ & References \\
\hline Lacy $M$ et al & $\mathrm{Pd}$ & $\begin{array}{l}\text { Relapsed \& refractory } \\
\text { disease/Phase I }\end{array}$ & 60 & $63 \%$ & $\begin{array}{l}\text { CR:5\% VGPR:28\% } \\
\text { PR:30\% }\end{array}$ & PFS:11.6 & J Clin Oncol 2009 \\
\hline Schey et al & $P$ & $\begin{array}{l}\text { Relapsed \& refractory } \\
\text { disease/Phase I }\end{array}$ & 24 & $54 \%$ & $\begin{array}{l}\text { CR:17\%VGPR:13\% } \\
\text { PR:25\% }\end{array}$ & Not reported & J Clin Oncol 2004 \\
\hline Streetly et al & $P$ & $\begin{array}{l}\text { Relapsed \& refractory } \\
\text { disease/Phase I }\end{array}$ & 20 & $50 \%$ & $\begin{array}{l}\text { CR:10\% VGPR:30\% } \\
\text { PR:10\% }\end{array}$ & PFS:10.5 OS:33 & Br J Haematol 2008 \\
\hline Lacy $M$ et al & $\mathrm{Pd}$ & $\begin{array}{l}\text { Lenalinomide \& bortezomib } \\
\text { refractory disease/Phase I }\end{array}$ & 34 & $50 \%$ & $\begin{array}{l}\text { VGPR:3\% PR:29\% } \\
\text { MR:18\% }\end{array}$ & Not reported & ASCO 2010 \\
\hline Richardson P et al & $\mathrm{Pd}$ & $\begin{array}{l}\text { Lenalinomide refractory } \\
\text { disease/Phase I }\end{array}$ & 32 & $52 \%$ & PR:28\% & Not reported & ASH 2009 \\
\hline
\end{tabular}


nine 4-week cycles of MPR followed by lenalidomide maintenance therapy until relapse or disease progression or MPR or MP without maintenance therapy. The median progression-free survival was significantly longer with MPR-R (31 months) than with MPR (14 months; $\mathrm{P}<0.001)$ or MP $(13$ months; $\mathrm{P}<0.001)$.

\section{Pomalidomide}

Pomalidomide is the newest IMiD that is undergoing clinical investigation (Table 8). Initial response rates for relapsed and refractory disease exceed expectation, even in the patients who have lenalidomide refractory disease $(\mathrm{PR}=32 \%)$. In an ongoing phase II study, patients who had failed both lenalidomide and bortezomib were given pomalidomide and dexamethasone. To date the response rates with this regimen exceed $50 \%$ with an OS of $86 \%$ after 6 months [53]. Treatment benefit with pomalidomide and low dose dexamethasone was also confirmed by another Phase II study in patients with multiple myeloma despite prior use of lenalidomide [54]. In a phase II trial presented at the 2011 American Society of Hematology meeting, 46 relapse and refractory patients treated with pomalidomide, dexamethasone, and clarithromycin (ClaPD), showed overall response rate of $60 \%$ with $27 \%$ showing very good partial remission [55]. Another study evaluating pomalidomide, cyclophosphamide, prednisone (PCP) in 41 patients with relapse refractory multiple myeloma including lenalidomide refractory patients show 59\% partial response including 2 patients achieving complete response [56]. More research is needed to establish the optimal treatment strategy and role of pomalidomide in patients with relapsed and refractory myeloma.

\section{Conclusion}

After over two decades with limited treatment options, numerous new regimens incorporating novel agents are now available for both transplant eligible and transplant ineligible patients with multiple myeloma. While response rates, adverse reactions and the optimal dosing strategy vary among the various IMiDs, there is increasing data to suggest that these novel agents and regimens are altering the natural history of the disease, improving the quality of life and longevity of patients with myeloma. Although teratogenicity is a significant concern and careful monitoring and precautions are required when using these agents, recent discoveries on the possible mechanism of thalidomide teratogenicity will hopefully lead to development of safer IMiDs [38]. Immunomodulatory drugs are a promising class of therapy for patients with multiple myeloma, both as single agents and in combination with conventional chemotherapy.

\section{Competing interests}

SZU has served as a consultant to Celgene, Millennium, and Onyx. SZU has received research funding from Celgene and Onyx, and speaking honoraria from Celgene and Millennium. TL has received speaking honoraria from Millennium.

\section{Authors' contributions}

All authors participated in preparation of the manuscript. All authors have read and approved the final manuscript.

\section{Author details}

${ }^{1}$ UC Cancer Institute, Division of Hematology-Oncology, University of Cincinnati School of Medicine, Cincinnati, OH, USA. ${ }^{2}$ Myeloma Institute for Research \& Therapy, University of Arkansas for Medical Sciences, 4301 W. Markham Street, Little Rock, AR, USA. ${ }^{3}$ Carolyn \& Neag Comprehensive Cancer Center, Lea's Center for Hematologic Disorders, University of Connecticut Health Center, Farmington, CT, USA.

Received: 17 July 2012 Accepted: 29 August 2012

Published: 11 September 2012

\section{References}

1. Kyle RA, Rajkumar SV: Multiple Myeloma. N Engl J Med 2004, 351:1860-1873.

2. Siegel R, Ward E, Brawley O, Jemal A: Cancer statistics, 2011: the impact of eliminating socioeconomic and racial disparities on premature cancer deaths. CA Cancer J Clin 2011, 61:212-236.

3. Solly S: Remarks on the pathology of mollities ossium with cases. Med Chir Trans 1844, 27:435-498. 8.

4. Durie BGM, Salmon SE: The current status and future prospects of treatment for multiple myeloma. Clinic in Haematology 1982, 11:181-210.

5. Blokhin N, Larionov L, Perevodchikova N, Chebotareva L, Merkulova N: Clinical Experiences With Sarcolysin In Neoplastic Diseases. Ann N Y Acad Sci 1958, 68:1128-1132.

6. Mass RE: A comparison of the effect of prednisone and a placebo in the treatment of multiple myeloma. Cancer Chemother Rep 1 1962, 16:257-259.

7. Sporn JR, Mclntyre OR: Chemotherapy of previously untreated multiple myeloma patients: an analysis of recent treatment results. Semin Oncol 1986, 13:318-325.

8. Singhal S, Mehta J, Desikan R, et al: Antitumor activity of thalidomide in refractory multiple myeloma. N Engl J Med 1999, 341:1565-1571.

9. Dimopoulos MA, Anagnostopoulos A, Weber D: Treatment of plasma cell dyscrasias with thalidomide and its derivatives. J Clin Oncol 2003, 21:4444-4454

10. Richardson $P$, Schlossman $R$, Jagannath $S$, et al: Thalidomide for patients with relapsed multiple myeloma after high-dose chemotherapy and stem cell transplantation: results of an open-label multicenter phase 2 study of efficacy, toxicity, and biological activity. Mayo Clin Proc 2004, 79:875-882.

11. Rajkumar SV, Rosinol L, Hussein M, et al: Multicenter, randomized, doubleblind, placebo-controlled study of thalidomide plus dexamethasone compared with dexamethasone as initial therapy for newly diagnosed multiple myeloma. J Clin Oncol 2008, 26:2171-2177.

12. Anderson KC: Lenalidomide and thalidomide: mechanisms of action-similarities and differences. Semin Hematol 2005, 42(4 Suppl 4):S3-S8. Review.

13. Dimopoulos M, Spencer A, Attal M, et al: Lenalidomide plus dexamethasone for relapsed or refractory multiple myeloma. $N$ Engl J Med 2007, 357:2123-2132.

14. Weber DM, Chen C, Niesvizky R, et al: Lenalidomide plus dexamethasone for relapsed multiple myeloma in North America. N Engl J Med 2007, 357:2133-2142.

15. Kumar S, Dispenzieri A, Lacy MQ, et al: Impact of lenalidomide therapy on stem cell mobilization and engraftment post-peripheral blood stem cell transplantation in patients with newly diagnosed myeloma. Leukemia 2007, 21:2035-2042.

16. Popat $U$, Saliba $R$, Thandi $R$, et al: Impairment of filgrastim-induced stem cell mobilization after prior lenalidomide in patients with multiple myeloma. iol Blood Marrow Transplant 2009, 15:718-723.

17. Attal M, Lauwers-Cances $V$, Marit $G$, et al: Lenalidomide maintenance after stem-cell transplantation for multiple myeloma. N Engl J Med 2012, 366 (19):1782-1791.

18. McCarthy PL, Owzar K, Hofmeister CC, et al: Lenalidomide after stem-cell transplantation for multiple myeloma. N Engl J Med 2012, 366 (19):1770-1781. 
19. Palumbo A, Hajek R, Delforge $M$, et al: Continuous lenalidomide treatment for newly diagnosed multiple myeloma. N Engl J Med 2012, 366(19):1759-1769.

20. Palumbo AP, Delforge M, Catalano J, et al: The incidence of second primary malignancies (SPM) in melphalan-prednisone-lenalidomide combination followed by lenalidomide maintenance (MPR-R) in newly diagnosed multiple myeloma patients (pts) aged 65 or older. J Clin Oncol 2011, 29:8007.

21. Rossi AC, Mark TM, Jayabalan D, et al: Incidence of second primary malignancies (SPM) after 6-years follow-up of continuous lenalidomide in first-line treatment of multiple myeloma (MM). J Clin Oncol 2011, 29:8008.

22. Dimopoulos MA, Orlowski RZ, Niesvizky R, Lonial S, Brandenburg NA, Weber DM: Lenalidomide and dexamethasone (LEN plus DEX) treatment in relapsed refractory myeloma (RRMM) patients and risk of second primary malignancy (SPM): Analysis of MM-009/010. J Clin Oncol 2011, 29:8009.

23. Schey SA, Fields P, Bartlett JB, et al: Phase I study of an immunomodulatory thalidomide analog, CC-4047, in relapsed or refractory multiple myeloma. J Clin Oncol 2004, 22:3269-3276.

24. Lacy MQ, Hayman SR, Gertz MA, et al: Pomalidomide (CC4047) plus lowdose dexamethasone as therapy for relapsed multiple myeloma. J Clin Oncol 2009, 27:5008-5014.

25. Streetly MJ, Gyertson K, Daniel Y, Zeldis JB, Kazmi M, Schey SA: Alternate day pomalidomide retains anti-myeloma effect with reduced adverse events and evidence of in vivo immunomodulation. Br J Haematol 2008 141:41-51.

26. Richardson $P$, Siegel $D$, Baz $R$, et al: A Phase1/2 muti-center, randomized, open label dose escalating study to determine the maximum tolerated dose, safety, and efficacy of pomalidomide alone or in combination with low-dose dexamethasone in patients with replased and refractory mutiple myeloma who have received prior treatment that includes lenalidomide and bortezomib. Blood 2009, 114:301.

27. Hideshima T, Chauhan D, Shima Y, et al: Thalidomide and its analogs overcome drug resistance of human multiple myeloma cells to conventional therapy. Blood 2000, 96:2943-2950.

28. Niwayama S, Turk BE, Liu JO: Potent inhibition of tumor necrosis factoralpha production by tetrafluorothalidomide and tetrafluorophthalimides. J Med Chem 1996, 39:3044-3045.

29. Chauhan D, Hideshima T, Rosen S, Reed JC, Kharbanda S, Anderson KC: Apaf-1/cytochrome c-independent and Smac-dependent induction of apoptosis in multiple myeloma (MM) cells. J Biol Chem 2001, 276:24453-24456.

30. Mitsiades N, Mitsiades CS, Poulaki V, et al: Biologic sequelae of nuclear factor-kappaB blockade in multiple myeloma: therapeutic applications. Blood 2002, 99:4079-4086.

31. Corral LG, Haslett PA, Muller G, et al: Differential cytokine modulation and $T$ cell activation by two distinct classes of thalidomide analogues that are potent inhibitors of TNF-alpha. J Immunol 1999, 163:380-386.

32. Schafer PH, Gandhi AK, Loveland MA, et al: Enhancement of cytokine production and AP-1 transcriptional activity in T cells by thalidomide-related immunomodulatory drugs. J Pharmacol Exp Ther 2003, 305:1222-1232.

33. Davies FE, Raje N, Hideshima T, et al: Thalidomide and immunomodulatory derivatives augment natural killer cell cytotoxicity in multiple myeloma. Blood 2001, 98:210-216.

34. Zhu D, Carrol LG, Fleming YW, Stein B: Immunomodulatory drugs Revlimid (lenalidomide) and CC-4047 induce apoptosis of both hematological and solid tumor cells through NK cell activation. Cancer Immunol Immunother 2008, 57:1849-1859.

35. Dredge K, Marriott JB, Macdonald CD, et al: Novel thalidomide analogues display anti-angiogenic activity independently of immunomodulatory effects. Br J Cancer 2002, 87:1166-1172.

36. Lu L, Payvandi $F, W u L$, et al: The anti-cancer drug lenalidomide inhibits angiogenesis and metastasis via multiple inhibitory effects on endothelial cell function in normoxic and hypoxic conditions. Microvasc Res 2009, 77:78-86

37. Escoubet-Lozach L, Lin IL, Jensen-Pergakes $\mathrm{K}$, et al: Pomalidomide and lenalidomide induce p21 WAF-1 expression in both lymphoma and multiple myeloma through a LSD1-mediated epigenetic mechanism. Cancer Res 2009, 69:7347-7356.

38. Ito $T$, Ando $H$, Suzuki $T$, et al: Identification of a primary target of thalidomide teratogenicity. Science 2010 Mar 12, 327(5971):1345-1350.
39. Girona AL, Mendy D, Miller $K$, et al: Direct binding with cereblon mediates the antiproliferative action of lenalidomide and pomalidomide. Blood 2011, 118:738

40. Zhu YX, Braggio $E$, Shi $C$, et al: Cereblon expression is required for the anti-myeloma activity of lenalidomide and Pomalidomide. Blood 2011 118:127.

41. Heintal D, Bolomsky A, Schreder M, et al: High expression of thalidomide binding protein cereblon(CRBN) is associated with improved clinical response in patients with mutiple myeloma treated with lenalidomide and dexamethasone. Blood 2011, 118:2879.

42. Palumbo A, Facon T, Sonneveld $P$, et al: Thalidomide for treatment of multiple myeloma: 10 years later. Blood 2008, 111:3968-3977.

43. Facon T, Mary JY, Hulin C, et al: Melphalan and prednisone plus thalidomide versus melphalan and prednisone alone or reducedintensity autologous stem cell transplantation in elderly patients with multiple myeloma (IFM 99-06): a randomized trial. Lancet 2008, 370:1209-1218.

44. Barlogie B, Anaissie E, van Rhee F, et al: Incorporating bortezomib into upfront treatment for multiple myeloma: early results of total therapy 3 . Br J Haematol 2007, 138(2):176-185.

45. Morgan GJ, Gregory WM, Davies FE, et al: The role of maintenance thalidomide therapy in multiple myeloma: MRC myeloma IX results and meta-analysis. Blood 2012, 119:7-15.

46. Rajkumar SV, Jacobus S, Callander NS, et al: Lenalidomide plus high-dose dexamethasone versus lenalidomide plus low-dose dexamethasone as initial therapy for newly diagnosed multiple myeloma: an open-label randomised controlled trial. Lancet Oncol 2010, 11:29-37.

47. Niesvizky R, Jayabalan DS, Christos PJ, et al: BiRD (Biaxin [clarithromycin]/ Revlimid [lenalidomide]/dexamethasone) combination therapy results in high complete- and overall-response rates in treatment-naive symptomatic multiple myeloma. Blood 2008, 111:1101-1109.

48. Palumbo A, Falco P, Corradini $P$, et al: Melphalan, prednisone, and lenalidomide treatment for newly diagnosed myeloma: a report from the GIMEMA-Italian Multiple Myeloma Network. J Clin Oncol 2007 25:4459-4465

49. Richardson P, Lonial S, Jakubowiak A, et al: Lenalidomide, bortezomib, and dexamethasone in patients with newly diagnosed multiple myeloma: Encouraging efficacy in high risk groups with updated results of a phase I/II study. Blood 2008, 112:92.

50. Richardson PG, Jagannath S, Jakubowiak AJ, et al: Phase II trail of lenalidomide, bortezomib and dexamethasone in patients (pts) with replased and replased/refractory multiple myeloma (MM): Updated efficacy and safety data after $>2$ years of follow up. Blood 2010, 116:3049.

51. Jakubowiak AJ, Reece DE, Hofmeister CC, et al: Lenalidomide, Bortezomib, Pegylated Liposomal Doxorubicin, and Dexamethasone in Newly Diagnosed Multiple Myeloma: Updated Results of Phase I/II MMRC Trial. Blood 2009, 114:132.

52. Kumar S, Flinn IW, Richardson PG, et al: Novel three- and four-drug combination regimens of bortezomib, dexamethasone, cyclophosphamide, and lenalidomide, for previously untreated multiple myeloma: Results from the multi-center, randomized, phase 2 EVOLUTION study. Blood 2010, 116:621.

53. Lacy MQ, Hayman SR, Gertz MA, et al: Pomalidomide (CC4047) plus low dose dexamethasone (Pom/dex) is active and well tolerated in lenalidomide refractory multiple myeloma (MM). Leukemia 2010 24:1934-1939.

54. Mikhael J, Rajkumar $V$, Roy $V$, et al: Efficacy of pomalidomide plus lowdose dexamethasone in mutiple myeloma patients despite previous use of lenalidomide. J Clin Oncol 2011, 29:8067.

55. Tomer M, Rodriguez M, Shah M, et al: ClaPD (Clarithromycin/ [Biaxin(R)], Pomalidomide, Dexamethasone) Therapy in Relapsed or Refractory Multiple Myeloma. Blood 2011, 118:635.

56. Palumbo A, Larocca A, Carella A, et al: A Phase I/II Study of PomalidomideCyclophosphamide-Prednisone (PCP) in Patients with Multiple Myeloma Relapsed/Refractory to Lenalidomide. Blood 2011, 118:632

doi:10.1186/2162-3619-1-27

Cite this article as: Latif et al:: Thalidomide and its analogues in the treatment of Multiple Myeloma. Experimental Hematology \& Oncology 2012 1:27. 